\title{
The effects of a solar eclipse on photo-oxidants in different areas of China
}

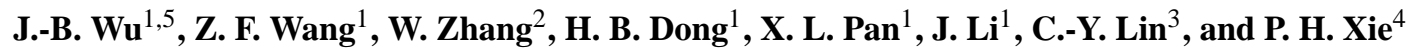 \\ ${ }^{1}$ State Key Laboratory of Atmospheric Boundary Layer Physics and Atmospheric Chemistry (LAPC), Institute of \\ Atmospheric Physics, Chinese Academy of Science, Beijing 100029, China \\ ${ }^{2}$ Aviation Meteorological Center of China, Beijing 100122, China \\ ${ }^{3}$ Research Center for Environmental Changes, Academia Sinica, Taipei, Taiwan \\ ${ }^{4}$ Key Lab. of Environment Optics \& Technology, Anhui Institute of Optics and Fine Mechanics, Chinese Academy of \\ Sciences, Hefei, China \\ ${ }^{5}$ Graduate University of Chinese Academy of Science, Beijing, China
}

Received: 31 December 2010 - Published in Atmos. Chem. Phys. Discuss.: 24 January 2011

Revised: 31 July 2011 - Accepted: 1 August 2011 - Published: 8 August 2011

\begin{abstract}
This study investigates the effects of the total solar eclipse of 22 July 2009 on surface ozone and other photooxidants over China. A box model was used to study the sensitivity of ozone to the limb darkening effect during an eclipse event, and to show that the impact on ozone is small (less than $0.5 \%$ ). In addition, the regional model WRFChem was applied to study the effects of the eclipse on meteorological and chemical parameters, focusing on different regions in China. Chemical and meteorological observations were used to validate the model and to show that it can capture the effects of the total solar eclipse well. Model calculations show distinct differences in the spatial distributions of meteorological and chemical parameters with and without the eclipse. The maximum impacts of the eclipse occur over the area of totality, where there is a decrease in surface temperature of $1.5^{\circ} \mathrm{C}$ and decrease in wind speed of $1 \mathrm{~m} \mathrm{~s}^{-1}$. The maximum impacts on atmospheric pollutants occur over parts of north and east China where emissions are greater, with an increase of $5 \mathrm{ppbv}$ in $\mathrm{NO}_{2}$ and $25 \mathrm{ppbv}$ in $\mathrm{CO}$ and a decrease of $10 \mathrm{ppbv}$ in $\mathrm{O}_{3}$ and $4 \mathrm{ppbv}$ in NO. This study also demonstrates the effects of the solar eclipse on surface photo-oxidants in different parts of China. Although the sun was obscured to a smaller extent in polluted areas than in clean areas, the impacts of the eclipse in polluted areas are greater and last longer than they do in clean areas. In contrast, the change in radical concentrations $\left(\mathrm{OH}, \mathrm{HO}_{2}\right.$ and $\mathrm{NO}_{3}$ ) in clean areas is much larger than in polluted areas mainly because of the limited source of radicals in these ar-
\end{abstract}

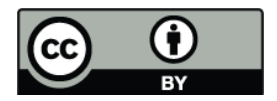

Correspondence to: Z. F. Wang (zifawang@mail.iap.ac.cn) eas. The change in radical concentrations during the eclipse reveals that nighttime chemistry dominates in both clean and polluted areas. As solar eclipses provide a natural opportunity to test more thoroughly our understanding of atmospheric chemistry, especially that governed by photolysis, a comprehensive experimental campaign during a future solar eclipse is highly desirable.

\section{Introduction}

Solar eclipses provide a rare and challenging opportunity to investigate how meteorological and photochemical processes respond to abrupt changes in incident solar radiation. Temperature, solar irradiance, relative humidity, wind and cloudiness within the surface layer are among the most common meteorological parameters explored by previous studies of solar eclipses (Fernandez et al., 1993, 1996; Hanna, 2000; Psiloglou and Kambezidis, 2007; Emde and Mayer, 2007; Kazadzis et al., 2007). The drop in surface temperature during a solar eclipse is of broad interest and becomes noticeable when the sun is about half covered (Anderson, 1999). Most studies find similar patterns of temperature change, with the lowest values occurring a few minutes after maximum solar coverage, but the reduction experienced may not be directly determined by the magnitude of the eclipse, but by the surrounding environment and local conditions (Founda et al., 2007; Gerasopoulos et al., 2008). Recent research into the meteorological effects of solar eclipses reveals a decrease in mean wind speed during an eclipse, and this is attributed to the combined effect of a decrease in the thermal gradient and

Published by Copernicus Publications on behalf of the European Geosciences Union. 
the stabilization of the surface layer due to the temperature drop (Amiridis et al., 2007).

Solar eclipses also enable evaluation of the response of the gas-phase chemistry of atmospheric photo-oxidants to a large, short-term perturbation in solar radiation. Plausible variations in stratospheric composition caused by solar eclipses have been addressed by earlier studies (Mims and Mims, 1993; Zerefos et al., 2000; Gogosheva et al., 2002). Previous studies have also focused on the effects on tropospheric ozone and other photo-oxidants. A decrease in surface ozone concentration was observed during a number of solar eclipse events (Srivastava et al., 1982; Tzanis, 2005; Zanis et al., 2001). In the solar eclipse of 11 August 1999, there was a time lag between the maximum of the eclipse and the maximum of the induced ozone decrease (Zerefos et al., 2001). Abram et al. (2000) describe hydroxyl radical and ozone measurements during the solar eclipse of 1999 and show that the $\mathrm{OH}$ concentration was well correlated $(r=0.88)$ to its rate of primary production from ozone photolysis. In the same event, the partitioning of $\mathrm{NO}_{\mathrm{x}}$ between $\mathrm{NO}$ and $\mathrm{NO}_{2}$ was determined almost exclusively by variations in $J \mathrm{NO}_{2}$ (Fabian et al., 2001). More recently in the total solar eclipse of 29 March 2006, observations and modeling show that there was a significant decrease in $\mathrm{O}_{3}$ and $\mathrm{NO}$ and an increase in $\mathrm{NO}_{2}$ at polluted sites, but no clear impact on these pollutants at unpolluted sites (Zanis et al., 2007). The decrease in the surface ozone concentration that was observed after the beginning of the eclipse lasted two hours, probably due to the decreased efficiency of photochemical ozone formation (Tzanis et al., 2008).

Although the most important chemical mechanisms controlling atmospheric composition have been identified and studied, further investigation is necessary to explain the complex interactions involving meteorological, topographic, emission and chemical parameters (Varotsos, 1994, 2005). In addition, solar eclipses are unique since they happen in different seasons, at different times of day, in different locations and under different synoptic conditions. On 22 July 2009 a total solar eclipse was visible along a narrow band across China from western Asia to the Pacific Ocean (Fig. 1b), while a partial eclipse was seen within a much broader area along the main axis which covered most of eastern Asia and the Pacific Ocean. After leaving mainland Asia, the path curved southeastward across the Pacific Ocean. More details on the path of this eclipse and its local circumstances can be found at the NASA eclipse web site (http://eclipse.gsfc.nasa. gov/SEmono/TSE2009/TSE2009.html). The umbral shadow of this eclipse first touched down in China at 08:56 Beijing Time (BJT) and left the mainland at 11:04 BJT after more than $2 \mathrm{~h}$ over China, and this may have had a significant impact on atmospheric composition. This eclipse provides a natural perturbation to atmospheric chemistry that allows us to test our understanding more thoroughly.
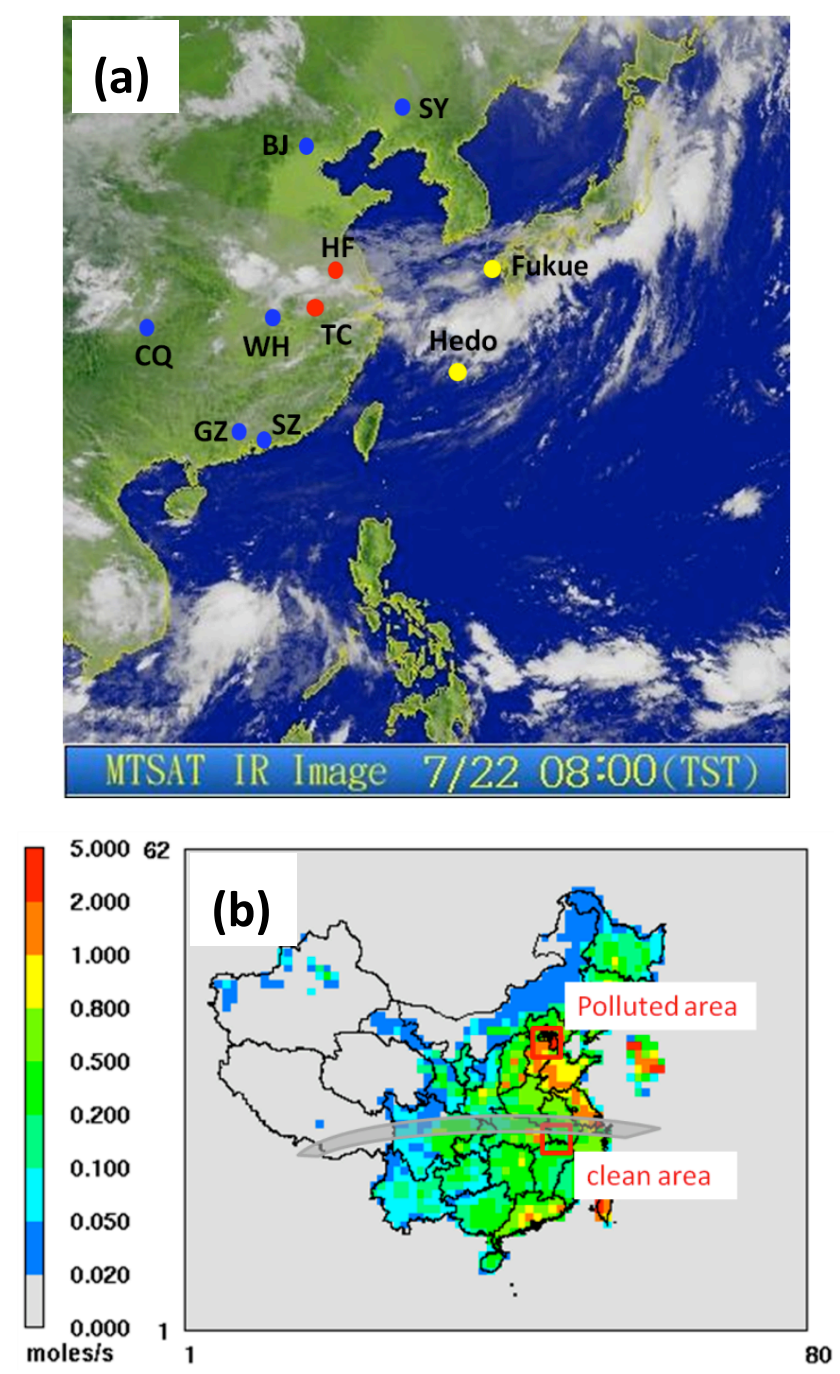

Fig. 1. (a) Satellite image at the beginning of the solar eclipse (08:00 BJT, 22 July 2009); blue points represent observation sites with 2-m temperature data, yellow points represent sites with downward solar radiation data, and red points represent sites with atmospheric pollutant data; (b) domains for WRF-Chem simulation with $\mathrm{NO}_{2}$ emission rates (moles $\mathrm{s}^{-1}$ ) from the SMOKE model; the red box represents two areas with different emission levels, and the shaded zone shows the path of the total solar eclipse across China. The domain-averaged maximum sun coverage is $74.1 \%$ in the polluted area and $96.8 \%$ in the clean area.

The present study investigates the chemical changes occurring during the total solar eclipse of 22 July 2009, focusing on surface ozone and other photo-oxidants in different parts of China. A box model was first used to test the sensitivity of ozone to the limb darkening effect, which is described in Sect. 2. In order to simulate the changes in both meteorological and chemical variables during the eclipse, an online numerical approach was adopted using the WRFChem model. A full description of the method used and validation of the model is given in Sect. 3; Sect. 4 describes 
the main results of the experiments and the conclusions are presented in Sect. 5.

\section{Sensitivity analysis of the limb darkening effect}

At different times during an eclipse, the disk of the moon covers different parts of the limb and the center of the sun. This limb darkening is spectrally dependent because radiation from the limb of the solar disk is less intense than that from the centre. Thus the spectral composition of the irradiance of the sun changes during the eclipse (Emde and Mayer, 2007; Kazantzidis et al., 2007; Koepke et al., 2001).

Based on consideration of radiative transfer within the solar atmosphere, the limb darkening can be expressed as a function of $r$, the relative distance from the centre of the solar disk (Waldmeier, 1941; Scheffler, 1974),

$\Gamma_{\gamma}(r)=\frac{1+\beta_{\gamma} \sqrt{1-r^{2}}}{1-\beta_{\gamma}}$

where $r=0$ represents the centre and $r=1$ the limb of the sun. The limb darkening coefficient $\beta_{\gamma}$ is a function of wavelength (Waldmeier, 1941):

$\beta_{\gamma}=\frac{3 \cdot h \cdot c \cdot \sqrt[4]{2}}{8 \cdot k \cdot \gamma \cdot T_{\mathrm{s}}}$

where $\gamma$ is the wavelength in $\mathrm{m}, h$ is the PLANCK constant $\left(6.63 \times 10^{-34} \mathrm{~J} \mathrm{~s}^{-1}\right), c$ is the speed of light $(2.998 \times$ $\left.10^{8} \mathrm{~m} \mathrm{~s}^{-1}\right), k$ is the Boltzmann constant $\left(1.38 \times 10^{-23} \mathrm{~J} \mathrm{~K}^{-1}\right)$ and $T_{\mathrm{S}}$ is the temperature of the sun's surface $(5740 \mathrm{~K})$.

Using $\Gamma_{\gamma}(r)$ from Eq. (1) and the mathematical approach described in Koepke et al. (2001), the normalized irradiance $I_{\text {norm }}$ during an eclipse can be calculated as the ratio between the irradiance of the remaining part of the sun and the irradiance of the uncovered solar disk.

Figure 2a shows the decrease in $I_{\text {norm }}$ with decreasing obscuration of the sun by the moon, $X$. The bold grey line represents the normalized intensity of a hypothetical sun without limb darkening (noLD). $I_{\text {norm }}(\gamma)$ is wavelength dependent because of limb darkening. These wavelengths are chosen to cover the spectral range of interest: $310 \mathrm{~nm}$ is important for the photochemical processes of $\mathrm{O}_{3}$ and $\mathrm{NO}_{2}, 550 \mathrm{~nm}$ is a standard wavelength for visible light, and $1500 \mathrm{~nm}$ is representative of the infrared. Compared to conditions with no limb darkening, the normalized radiation for each wavelength, $I_{\text {norm }}(\gamma)$, is enhanced when the distance between the centers of the sun and moon is larger than $0.5(|X|>0.5)$. During the time when the limb of the sun is covered by the moon, the brighter central region of the sun still emits a lot of radiation. When the central parts of the sun are obscured by the moon $(|X|<0.5), I_{\text {norm }}(\gamma)$ at each wavelength is lower than in noLD because the radiation in these regions is blocked.
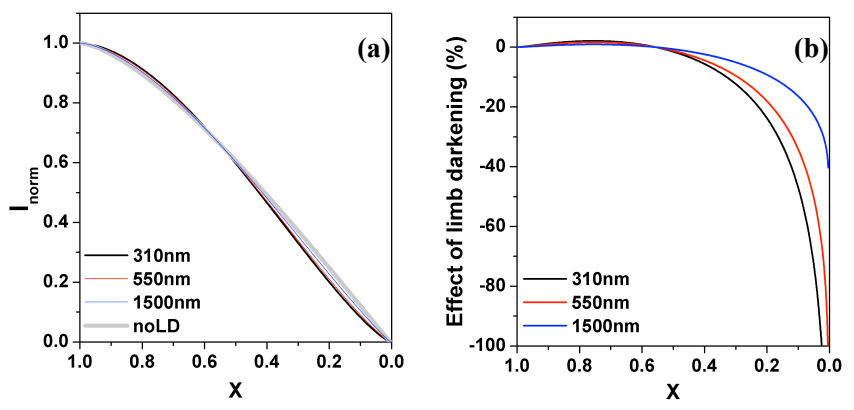

Fig. 2. (a) Normalized radiation as a function of $X$, the distance between the centers of the sun and moon, during the eclipse for different wavelengths; (b) Effect of limb darkening as a function of $X$ for different wavelengths (calculated using Eq. (3) in the text).

Figure $2 b$ presents the spectral dependence of solar radiation during the eclipse compared to the case with no limb darkening, which is calculated using:

$\left\{I_{\text {norm }}(\gamma)-I_{\text {norm }}(\operatorname{noLD})\right\} / I_{\text {norm }}(\gamma) \times 100 \%$

It is clear that shorter wavelengths are affected more by the limb darkening effect. The reduction in radiation is more significant when close to the central part of the eclipse. When $|X|>0.9, I_{\text {norm }}(\gamma)$ is reduced by more than $60 \%, 30 \%$ and $10 \%$ at $310 \mathrm{~nm}, 550 \mathrm{~nm}$ and $1500 \mathrm{~nm}$ respectively.

Therefore, the spectral dependence of radiation due to the limb darkening of the sun may be important during a solar eclipse. It is necessary to investigate how this limb darkening affects surface ozone. A CBM-Z chemical box model (Zeveri et al., 1999) is used to carry out three sensitivity experiments, which are listed in Table 1.

It is known that $310 \mathrm{~nm}$ is important for the photochemical processing of $\mathrm{O}_{3}$ and $\mathrm{NO}_{2}$, and photolysis rates are directly influenced by solar radiation at this wavelength. Therefore, the photolysis rate can be scaled by the reduction of $I_{\text {norm }}(310 \mathrm{~nm})$ shown in Fig. $2 \mathrm{a}$. It should be noted that Fig. 2a shows only half of an eclipse event, and that the same occurs as the moon leaves the sun gradually. Figure 3a shows the photolysis rate of ozone $\left(J \mathrm{O}^{1} \mathrm{D}, \mathrm{s}^{-1}\right)$ in three sensitivity experiments during a solar eclipse event. The $J \mathrm{O}^{1} \mathrm{D}$ value in the Non-Eclipse experiment displays a steady increase in the morning, while in the Eclipse-LD and Eclipse-noLD experiments there is a reduction during the eclipse period. The difference in $J \mathrm{O}^{1} \mathrm{D}$ between Eclipse-LD and Eclipse-noLD is the same scale as the difference in $I_{\text {norm }}(\gamma)$ between $310 \mathrm{~nm}$ and noLD (Fig. 2a).

In Kazantzidis (2007), a radiative transfer model was used for computation of a correction for the total ozone measurements due to the limb darkening. This correction was found to be too small (less than $0.01 \%$ ) to explain the large decrease in total ozone column. Here we confirm this finding by considering the ozone concentration from the box model (Fig. 3). The ozone concentration in the Non-Eclipse run 
Table 1. Sensitivity experiments performed with the box model.

\begin{tabular}{ll}
\hline case & description \\
\hline Non-Eclipse & Normal radiation according to solar zenith angle \\
Eclipse-LD & Reduced radiation with limb darkening effect (black line in Fig. 2a) \\
Eclipse-noLD & Reduced radiation without limb darkening effect (grey line in Fig. 2a) \\
\hline
\end{tabular}
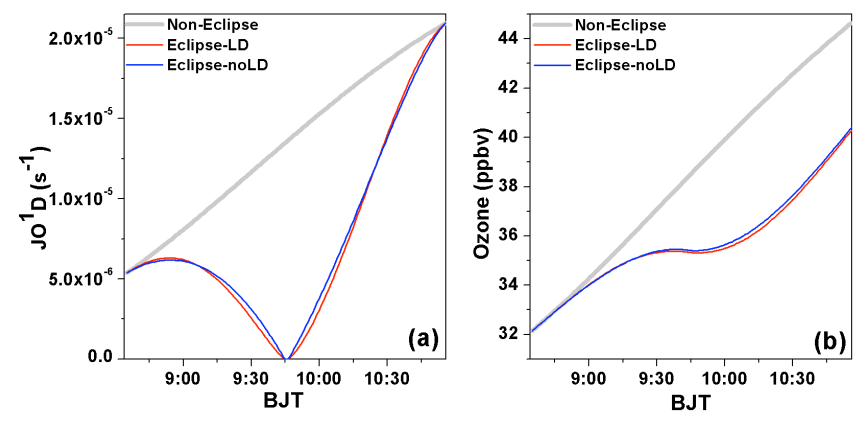

Fig. 3. Photolysis rate of ozone, $J \mathrm{O}^{1} \mathrm{D},($ a) and ozone concentration (b) in the three sensitivity experiments.

shows a steady increase during the solar eclipse period, while Eclipse-LD and Eclipse-noLD results show a slight decrease. It is worth noting that the Eclipse-LD and Eclipse-noLD results are almost the same, with only a slightly greater decrease in the Eclipse-LD experiment. The effect of limb darkening on surface ozone is less than $0.5 \%$. Although the relative effect of limb darkening on shorter wavelengths is larger (Fig. 2b), the absolute difference in the reduction in solar radiation between short and long wavelength is small (Fig. 2a). This small perturbation leads to little change in surface ozone between the Eclipse-LD and Eclipse-noLD experiments. Therefore, we conclude that the effect of limb darkening on surface ozone is too small to explain the large decrease in surface ozone during a solar eclipse event.

\section{Description and validation of the regional model}

\subsection{Method}

Numerical simulations were carried out using the WRFChem model, version 3.1.1. The WRF-Chem model is a newly developed regional chemical transport model coupled online with the Weather Research and Forecasting (WRF) model. The WRF model is a fully compressible, nonhydrostatic model and a detailed description can be found on the WRF model website at http://www.wrf-model.org. The chemistry model is fully coupled with the WRF model, with the same vertical and horizontal coordinates, time step, transport scheme, and physical parameterization schemes. A detailed description of WRF-Chem is given by Grell et al. (2005) and Fast et al. (2006), and more information can be found at the website (http://ruc.noaa.gov/wrf/WG11/).

The WRF-Chem model used in this study has a vertical structure consisting of $27 \sigma$-levels extending from 1000 to $50 \mathrm{hPa}$, and a horizontal resolution of $81 \mathrm{~km}$ in the coarse domain and $27 \mathrm{~km}$ in two nested domains (Fig. 1b). The following model parameterizations have been chosen to simulate atmospheric conditions:

- the Rapid Radiative Transfer Model, RRTM, (Mlawer, 1997) was used as the solver for long wave radiation and the Dudhia scheme (Dudhia, 1989) for the short wave. In this study, the radiation modules were called every minute to account for the parameterization of the eclipse which was inserted into this module,

- the Mellor-Yamada-Janjic TKE scheme for turbulence in the PBL and in the free atmosphere (Janjic, 1994),

- the Lin microphysics scheme was used to simulate atmospheric microphysics,

- the CBM-Z chemical mechanism (Zaveri et al., 1999) and MOSAIC aerosol module (Zaveri et al., 2008) were used to simulate the chemical conditions,

- the Fast-J photolysis scheme (Wild et al., 2000; Barnard et al., 2004) was used to calculate photolysis rates, and the module was called every minute for consistency with the radiation schemes.

The Sparse Matrix Operator Kernel Emissions (SMOKE) model is applied to process the emissions and to provide gridded emission data for the WRF-Chem model. Two emission inventories are considered in this study: regional emissions at $10 \mathrm{~km}$ resolution from the TRACE-P emission inventory (Streets et al., 2003) updated according to personal communications, and power plant emission data from INTEX-B at a horizontal resolution of $0.5^{\circ} \times 0.5^{\circ}$ (Zhang et al., 2009). To obtain a better distribution of emissions, area emissions over East Asia have been spatially allocated based on related spatial factors such as population data from the Land Scan 2005 Global Population Database. The road dust emission is spatially distributed according to road length.

There are two major obstacles in reproducing the solar eclipse phenomenon and its effects on the atmosphere using a numerical model: 
1. Inserting the eclipse path (including total and partial eclipse) into the model, and following its progression across the Earth during the day.

2. Calculating the percentage obscuration during the eclipse corresponding to the latitude and longitude of each grid point in the simulation domain every timestep.

Reproduction of the solar eclipse in the WRF-Chem model was solved by varying the solar radiation and photolysis rates using a scaling factor. This scaling factor was determined by the solar coverage expressed as a function of latitude, longitude, time and wavelength. For example, the obscuration of the sun at each grid point is proportional to the distance from the center of the total eclipse at a given time. The distance of each grid point to the center of the total eclipse was calculated with a unified formula referred to the path of the umbral shadow observed by NASA (http://eclipse.gsfc.nasa.gov/SEmono/TSE2009/ TSE2009tab/TSE2009-Table03.pdf). Since the moon's umbral shadow moved with a known velocity across the Earth, the obscuration at each grid point is rescaled at each time step. In addition, the limb darkening effect is introduced in this scaling factor so that shorter wavelength radiation is reduced slightly more at a given obscuration (see Sect. 2). The variable $J_{\text {ecl }}$ during the eclipse is then calculated from the original $J_{\text {orig }}$ multiplied by the scaling factor:

$J_{\text {ecl }}=J_{\text {orig }} \cdot$ factor (lat, lon, time, wavelength)

This method was applied in the radiation and photolysis scheme every minute during the eclipse period (08:5512:15 BJT) to simulate the passage of the solar eclipse.

In order to investigate the effects of the solar eclipse on meteorological and chemical parameters, the WRF-Chem modeling system was run twice, once with the moving umbra of the Moon (Eclipse), and once without it (NoEclipse).

\subsection{Validation experiment}

Observation sites are shown in Fig. 1a, with yellow points representing sites with downward solar radiation data, blue points representing sites with 2-m temperature, and red points representing sites with atmospheric pollutant measurements. The downward solar radiation data is obtained from SKYNET (http://atmos.cr.chiba-u.ac.jp/). The surface air temperature data is collected from observations at airports with $1 \mathrm{~min}$ time resolution. Atmospheric pollutant data for $\mathrm{O}_{3}$ and $\mathrm{NO}_{2}$ is obtained from local measurements in Hefei and Tongcheng with $5 \mathrm{~min}$ time resolution. From the satellite image (Fig. 1a), it can be seen that the sites at Wuhan (WH), Tongcheng (TC), Hefei (HF), Hedo and Fukue are influenced by light cloud cover. However, there is no rain during the solar eclipse period according to the local observations. Therefore the observation data is appropriate for comparison with WRF-Chem simulations.
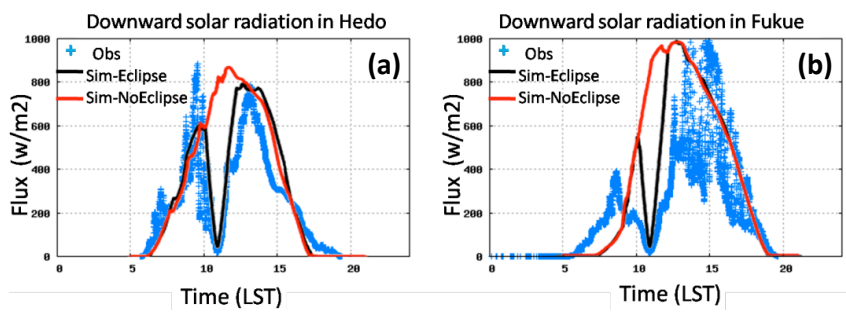

Fig. 4. Downward solar radiation flux $\left(\mathrm{w} \mathrm{m}^{-2}\right.$ ) during the day of the eclipse at (a) Hedo $(26.87 \mathrm{~N}, 128.25 \mathrm{E})$ and (b) Fukue (32.75 N, $128.68 \mathrm{E}$ ) which are shown as yellow points in Fig. 1a.

\subsubsection{Downward solar radiation}

The immediate effect of the solar eclipse is on solar radiation. The variation in the downward solar radiation is approximately proportional to the obscuration of the sun. The temporal variation of the downward solar radiation (Fig. 4) shows a sharp decrease at Hedo and Fukue both in the observations and the Eclipse run, while in the NoEclipse run no reduction in radiation is seen. Clearly the Eclipse run is capable of reproducing the downward solar radiation well when compared to measured data.

\subsubsection{Temperature at $2-\mathrm{m}$}

The time series of observed and simulated 2-m temperature at different sites during the eclipse are shown in Fig. 5. Chongqing and Wuhan (Fig. 5c, d) lie in the path of the total solar eclipse, while other sites experienced a partial eclipse, with Beijing and Shenyang (Fig. 5a, b) lying approximately 10 degrees to the north and Guangzhou and Shenzhen (Fig. 5e, f) lying 7 degrees to the south. The percentages in the figure represent the maximum solar coverage during the eclipse period. The double arrows denote the maximum difference in temperature between the Eclipse and NoEclipse runs. The temperature drop followed a similar, clear pattern in both the observations and the Eclipse run at all stations, as shown in Fig. 5, while in the NoEclipse run the temperature generally increased without any drop. As well as the amplitude of the temperature drop, the timing of the simulated response is also consistent with the observations. The time of the minimum temperature occurrence at these sites is very close to the full phase of the solar eclipse. In addition, the amplitudes of the temperature changes are different at each location. The maximum difference in temperature between the Eclipse and NoEclipse run is $2.13^{\circ} \mathrm{C}$ and $2.04^{\circ} \mathrm{C}$ in Chongqing and Wuhan respectively (under the total eclipse), larger than that at stations with the partial eclipse. This is largely related to the different percentage of obscuration. Generally, the results of the Eclipse run agree quite well with measured data during the eclipse. 

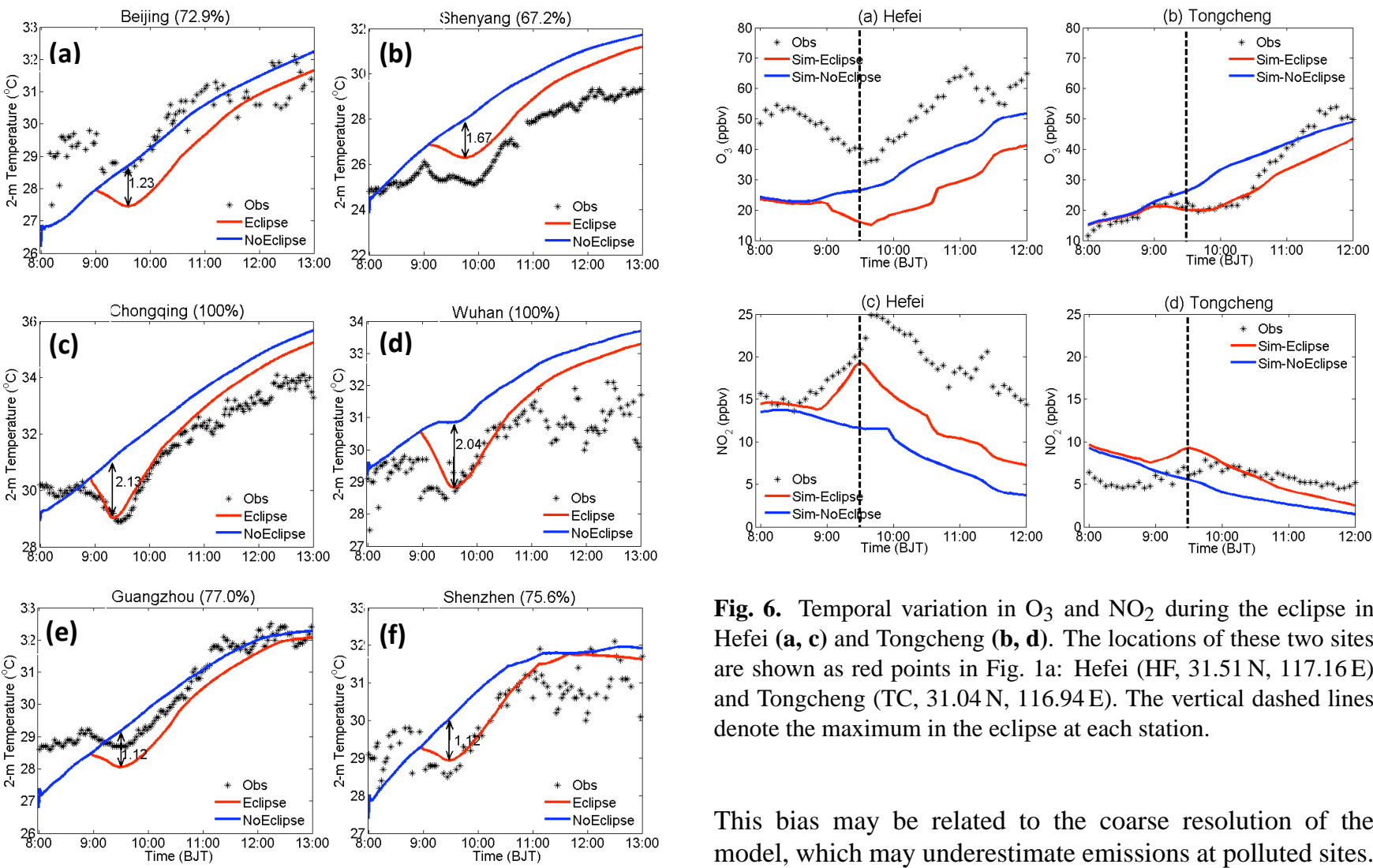

Fig. 5. Temporal variation of $2-\mathrm{m}$ temperature during the eclipse at the airports at (a) Beijing, (b) Shenyang, (c) Chongqing, (d) Wuhan, (e) Guangzhou, and (f) Shenzhen. The double arrows denote the maximum difference in temperature between the Eclipse and NoEclipse runs. The percentage in each title represents the maximum solar coverage during the eclipse period. The locations of each airport are shown as blue points in Fig. 1a: Beijing (BJ, $40.08 \mathrm{~N}$, 116.61 E), Shenyang (SY, 41.64 N, 123.48E), Chongqing (CQ, $29.72 \mathrm{~N}, 106,64 \mathrm{E})$, Wuhan (WH, 30.37 N, 114.20 E), Guangzhou (GZ, 23.39 N, 113.31 E), Shenzhen (SZ, 22.64 N, 113.80 E).

\subsection{3 $\quad \mathrm{NO}_{2}$ and $\mathrm{O}_{3}$}

The performance of the Eclipse experiment for atmospheric pollutants is demonstrated for surface $\mathrm{O}_{3}$ and $\mathrm{NO}_{2}$ at Hefei and Tongcheng, which are located in the path of the total eclipse and are characterized by different air pollution levels. During the eclipse hours, observations of surface ozone displayed a decrease of around $20 \mathrm{ppbv}$ in Hefei, while at the relatively unpolluted site of Tongcheng the decrease was much smaller. The measured $\mathrm{NO}_{2}$ showed an increase of up to 10 and 3 ppbv in Hefei and Tongcheng respectively. At the polluted site (Hefei) the Eclipse experiment showed a decrease in ozone similar to that observed but lower in magnitude, with a maximum decrease of approximately $10 \mathrm{ppbv}$ (Fig. 6a). The maximum increase of $\mathrm{NO}_{2}$ at this site was about 5 ppbv, half of the change in observed $\mathrm{NO}_{2}$ (Fig. 6c).

Fig. 6. Temporal variation in $\mathrm{O}_{3}$ and $\mathrm{NO}_{2}$ during the eclipse in Hefei $(\mathbf{a}, \mathbf{c})$ and Tongcheng $(\mathbf{b}, \mathbf{d})$. The locations of these two sites are shown as red points in Fig. 1a: Hefei (HF, 31.51 N, 117.16E) and Tongcheng (TC, 31.04 N, 116.94 E). The vertical dashed lines denote the maximum in the eclipse at each station.

This bias may be related to the coarse resolution of the model, which may underestimate emissions at polluted sites. At the relatively unpolluted site of Tongcheng (Fig. 6b, d), the Eclipse run matched very well with observations both in magnitude and pattern. In general, the Eclipse experiment showed a very similar pattern in surface $\mathrm{O}_{3}$ and $\mathrm{NO}_{2}$ to that observed, while the NoEclipse run showed steady increases or decreases typical of normal conditions. The Eclipse run generally reproduces the main features of atmospheric pollutants observed during the solar eclipse.

In conclusion, based on the comparison between model simulations and measurements above, the Eclipse experiment captures the main characteristics of the solar eclipse and its effects on atmospheric composition.

\section{Results of experiments}

\subsection{Total effects of the solar eclipse}

The effects of the solar eclipse over China as calculated with WRF-Chem are depicted in Fig. 7 which shows the difference in 2-m temperature, surface wind speed, $\mathrm{NO}_{2}, \mathrm{CO}, \mathrm{O}_{3}$, and NO between Eclipse and NoEclipse conditions for the lowest model level averaged over the time period 09:00 10:00 BJT.

The simulated temperature response (Fig. 7a) is distinct over mainland China with more pronounced anomalies (about $-1.5^{\circ} \mathrm{C}$ ) over the totality areas in central China, while the effect of the eclipse is minimized by the sea due to its greater heat capacity. In addition, there is a zone with 

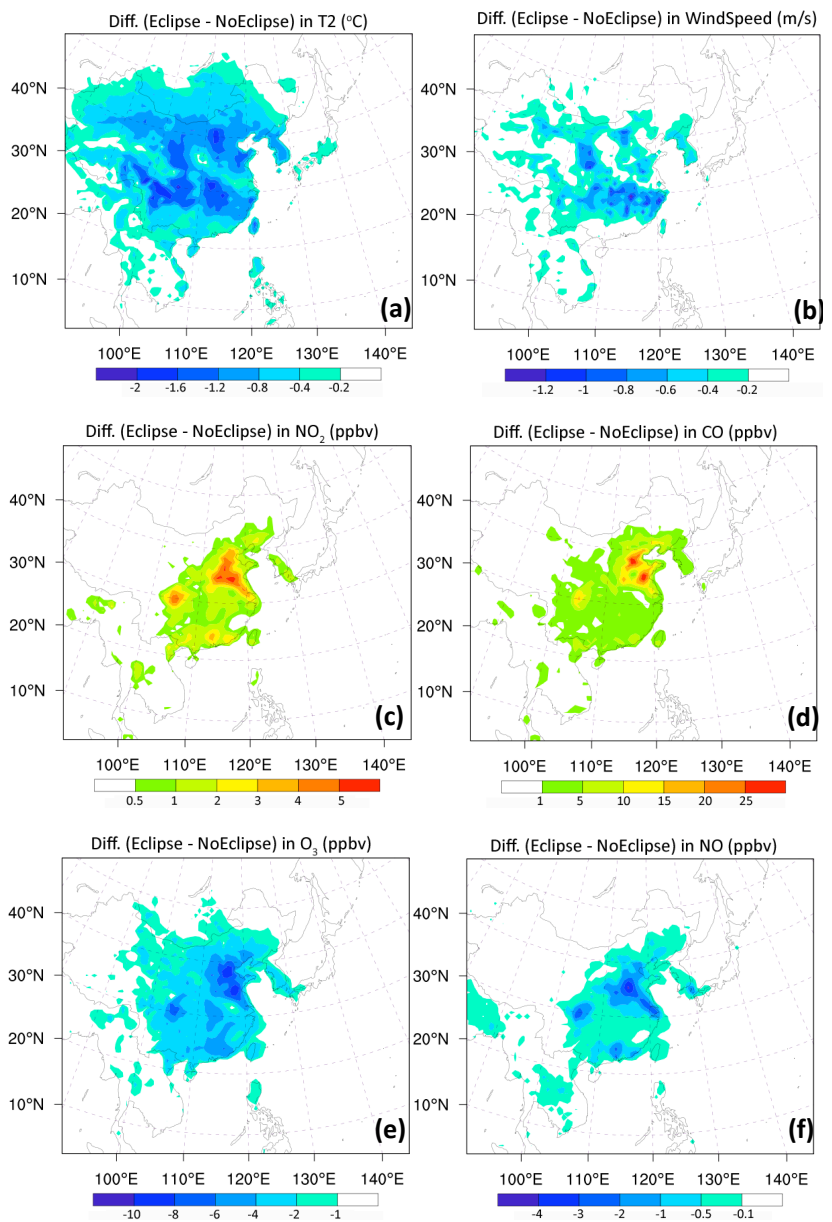

Fig. 7. Differences in (a) temperature, (b) wind speed, (c) $\mathrm{NO}_{2}$, (d) $\mathrm{CO}$, (e) $\mathrm{O}_{3}$, and (f) $\mathrm{NO}$ between Eclipse and NoEclipse conditions in the WRF-Chem simulations averaged over the time period of the eclipse, 09:00-10:00 BJT (Beijing Time).

reduced temperature differences between north and central China resulting from cloud coverage, which greatly reduces the impact of the eclipse. The location of this zone is consistent with cloud cover in the satellite image (Fig. 1a), which suggests that the simulation of the eclipse is reasonable. It can be concluded that the magnitude of the surface air temperature is not just dependent on solar obscuration induced by the eclipse but on a combination of several factors including solar obscuration, vegetation and local cloudiness.

The simulated wind speed response (Fig. 7b) shows a similar pattern to temperature, with a decrease of approximately $1 \mathrm{~m} \mathrm{~s}^{-1}$ over the area of totality. It is worth noting that the reduction in wind speed is larger when the air temperature over an area decreases by more than $1^{\circ} \mathrm{C}$. This may result from the combined effect of a decrease in the thermal gradient and the stabilization of the surface layer induced by the temperature drop.
In contrast to the meteorological variables, the impacts of the solar eclipse on atmospheric pollutants (Fig. 7c-f) are greatest over parts of north and east China where the maximum emissions occur. We find an increase of $5 \mathrm{ppbv}$ in $\mathrm{NO}_{2}$ and $25 \mathrm{ppbv}$ in $\mathrm{CO}$, and a decrease of $10 \mathrm{ppbv}$ in $\mathrm{O}_{3}$ and 4 ppbv in NO. Solar radiation changes during an eclipse may affect tropospheric photo-oxidants in several ways on different timescales. A perturbation to the photo-stationary steady state of $\mathrm{O}_{3}, \mathrm{NO}$ and $\mathrm{NO}_{2}$ is induced immediately during a solar eclipse through Reactions (R1-R3):

$$
\begin{aligned}
& \mathrm{NO}_{2}+h v(\lambda<424 \mathrm{~nm}) \rightarrow \mathrm{O}\left({ }^{3} \mathrm{P}\right)+\mathrm{NO} \\
& \mathrm{O}\left({ }^{3} \mathrm{P}\right)+\mathrm{O}_{2}+\mathrm{M} \rightarrow \mathrm{O}_{3}+\mathrm{M} \\
& \mathrm{NO}+\mathrm{O}_{3} \rightarrow \mathrm{NO}_{2}+\mathrm{O}_{2}
\end{aligned}
$$

As a direct consequence the primary pollutant NO destroys $\mathrm{O}_{3}$ through the titration Reaction (R3) without $\mathrm{O}_{3}$ being reformed through $\mathrm{NO}_{2}$ photolysis Reaction (R1). Therefore, the photo-stationary steady state of $\mathrm{O}_{3}, \mathrm{NO}$ and $\mathrm{NO}_{2}$ is very susceptible to solar radiation changes during an eclipse, as shown clearly in Fig. 7c-e. The increase of CO may be related to dynamical processes, as discussed below.

During the eclipse period, it can be concluded that the eclipse has clear impacts on atmospheric pollutants over high-emission areas and on meteorological variables around the areas of totality.

\subsection{Effects in different areas}

The results discussed in the previous sections indicate that the effects of the solar eclipse are significant. In particular, since the results of the Eclipse and NoEclipse experiments suggest that the eclipse can have a greater impact on atmospheric pollutants in areas with higher emissions even though solar obscuration is less, there is strong motivation to investigate the effects of the eclipse in different areas further. For this purpose, we focus on surface photo-oxidants in two areas with different emission levels (Fig. 1b). The area in north China, referred to here as the "polluted area", has a higher emission level than the area in central China (termed the "clean area"). Furthermore, the maximum solar obscuration is different in these two areas, averaging $74.1 \%$ in the polluted area and $96.8 \%$ in the clean area. These two areas are little affected by cloud (shown in the satellite image, Fig. 1a) which could greatly reduce the effect of the eclipse. Based on the distinct characteristics in these two areas, we can gain a clear understanding of the effects of the eclipse.

The average differences in $\mathrm{O}_{3}, \mathrm{NO}_{2}$ and $\mathrm{NO}$ between Eclipse and NoEclipse conditions in the WRF-Chem simulations over the time period of the eclipse (08:00-13:00 BJT) are given in Table 2 . In the polluted area, the WRF-Chem simulations show an ozone decrease of $5.4 \mathrm{ppbv}$, almost twice that in the clean area. Similarly the WRF-Chem simulations indicate small changes in $\mathrm{NO}$ and $\mathrm{NO}_{2}$ in the clean 
Table 2. Average differences in $\mathrm{O}_{3}, \mathrm{NO}_{2}$ and $\mathrm{NO}$ between Eclipse and NoEclipse conditions in WRF-Chem simulations over the time period of the eclipse 08:00-13:00 Beijing Time (BJT). The values in parentheses correspond to the differences at maximum solar coverage.

\begin{tabular}{lrrrr}
\hline & $\Delta \mathrm{O}_{3}(\mathrm{ppbv})$ & $\Delta \mathrm{NO}_{2}(\mathrm{ppbv})$ & $\Delta \mathrm{NO}(\mathrm{ppbv})$ & $\Delta \mathrm{CO}(\mathrm{ppbv})$ \\
\hline Polluted area & $-5.4(-7.6)$ & $1.6(3.4)$ & $-0.3(-1.6)$ & $10.6(13.1)$ \\
Clean area & $-2.7(-4.5)$ & $0.7(1.7)$ & $-0.01(-0.8)$ & $2.5(3.6)$ \\
\hline
\end{tabular}
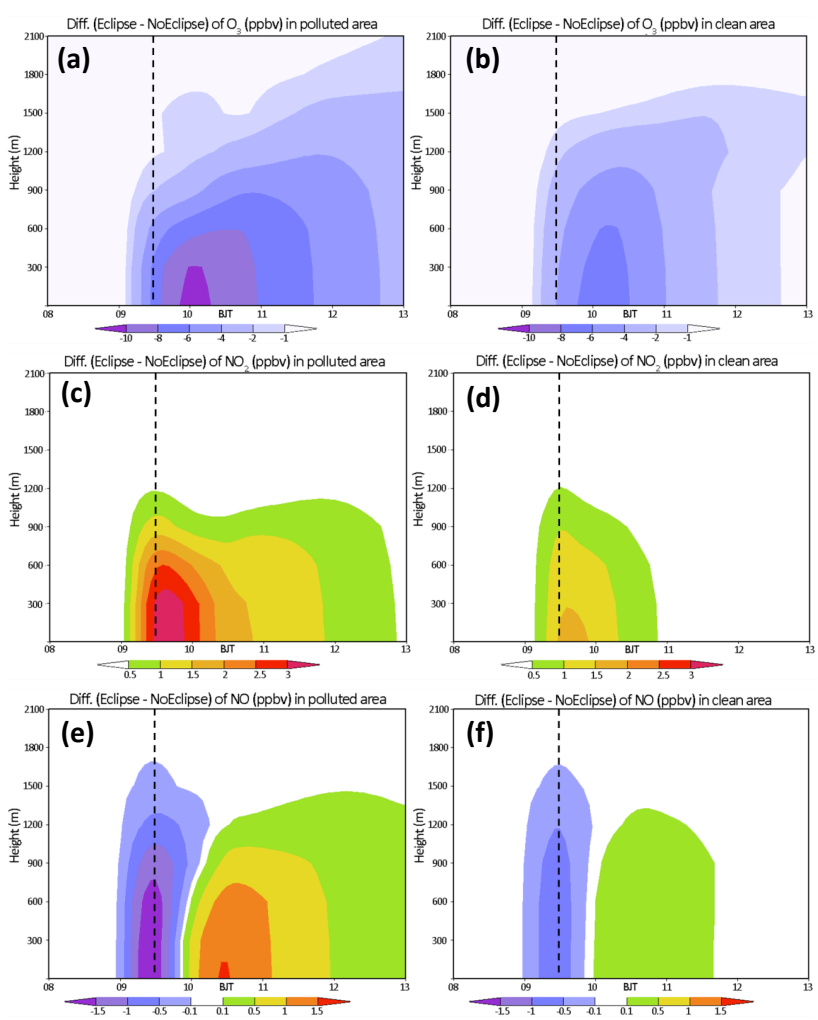

Fig. 8. Altitude-time cross sections of the differences between model simulations (Eclipse-NoEclipse) for (a, b) $\mathrm{O}_{3}$, (c, d) $\mathrm{NO}_{2}$, and (e, f) NO, averaged over the polluted (left side) and clean (right side) areas. Dashed lines show the time of maximum solar eclipse in Beijing.

area during the solar eclipse. In particular, an increase in $\mathrm{NO}_{2}$ of $3.4 \mathrm{ppbv}$ and decrease in NO of $1.6 \mathrm{ppbv}$ are calculated at the time of maximum solar coverage in the polluted area. The net effect on $\mathrm{O}_{3}, \mathrm{NO}_{2}$ and $\mathrm{NO}$ can be attributed to perturbation of the photostationary state of $\mathrm{O}_{3}, \mathrm{NO}_{2}$ and $\mathrm{NO}$ during the eclipse, with $\mathrm{NO}_{2}$ generated from the titration reaction of $\mathrm{O}_{3}$ with $\mathrm{NO}$ which is not then efficiently photolysed. During the solar eclipse over China, the response of $\mathrm{O}_{3}, \mathrm{NO}_{2}$ and $\mathrm{NO}$ in the polluted area is much larger than that in the clean area. In addition, we find an increase in $\mathrm{CO}$ of $10.6 \mathrm{ppbv}$ in the polluted area but only a small change in the clean area.
The altitude-time cross sections of the effects of the eclipse on $\mathrm{O}_{3}, \mathrm{NO}_{2}$, and $\mathrm{NO}$ in the polluted and clean areas are shown in Fig. 8. These show that:

- In the polluted area, the maximum responses of $\mathrm{O}_{3}$, $\mathrm{NO}_{2}$ and $\mathrm{NO}$ induced by solar eclipse are of the order of $10 \mathrm{ppbv}, 3 \mathrm{ppbv}$ and $-1.5 \mathrm{ppbv}$ respectively, while the corresponding values in the clean area are much smaller. Although the maximum solar obscuration is smaller in the polluted area than in clean area, the impacts of the eclipse in the polluted area are greater in magnitude, and last longer than those in the clean area.

- There is an increase in NO after the initial sharp decrease at the beginning of eclipse. $\mathrm{NO}_{2}$ is accumulated during the eclipse (see Fig. 8b), and photolysis of the accumulated $\mathrm{NO}_{2}$ once the solar radiation starts to recover generates extra NO, resulting in a sharp increase in NO that starts during the partial eclipse period once solar radiation reappears.

- The effect of the eclipse on atmospheric pollutants is mainly within the planetary boundary layer (below $1500 \mathrm{~m}$ ) as this is where the highest levels of atmospheric pollutants occur.

It is interesting to find that there is reduced $\mathrm{CO}$ directly above the enhanced layer of surface CO (Fig. 9), with almost the same magnitude of $\mathrm{CO}$ concentrations in these two regions. This can be attributed to the change in boundary layer height between the Eclipse and NoEclipse simulations (Fig. 9). The boundary layer height is suppressed during the eclipse period so that the emissions are not mixed up as high. Thus the concentration of $\mathrm{CO}$ within the mixing boundary layer is higher and free tropospheric concentrations lower. Although the change in $\mathrm{CO}$ in the clean area shows a very similar pattern to the polluted area, the magnitude of the $\mathrm{CO}$ concentration anomaly is much smaller in the clean area because of the lower emission rate.

The WRF-Chem model simulates a sharp change from daytime to nighttime chemistry as depicted in Fig. 10. During the eclipse period, hydroxyl $(\mathrm{OH})$ and hydroperoxy $\left(\mathrm{HO}_{2}\right)$ radicals, mainly produced through photochemistry, show a rapid decrease of more than an order of magnitude to reach nighttime levels. Simultaneously the model simulations show that the nitrate $\left(\mathrm{NO}_{3}\right)$ radical - mainly presents during the night - increases during the eclipse hours. 

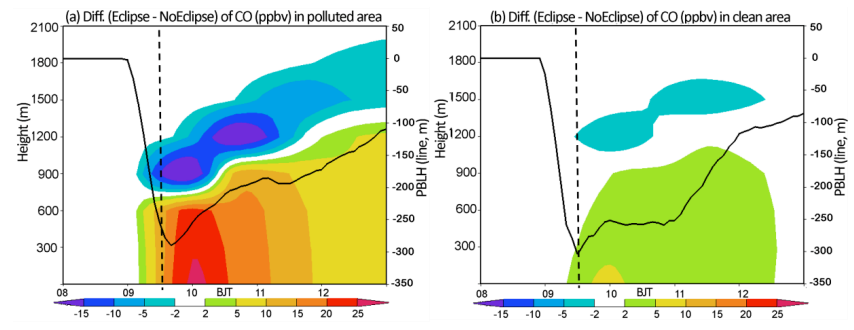

Fig. 9. Altitude-time cross sections of the differences between model simulations (Eclipse-NoEclipse) for $\mathrm{CO}$ averaged over the (a) polluted and (b) clean areas. The black lines represent differences in planetary boundary layer height between model simulations (Eclipse-NoEclipse) and dashed lines show the time of maximum solar eclipse in Beijing.

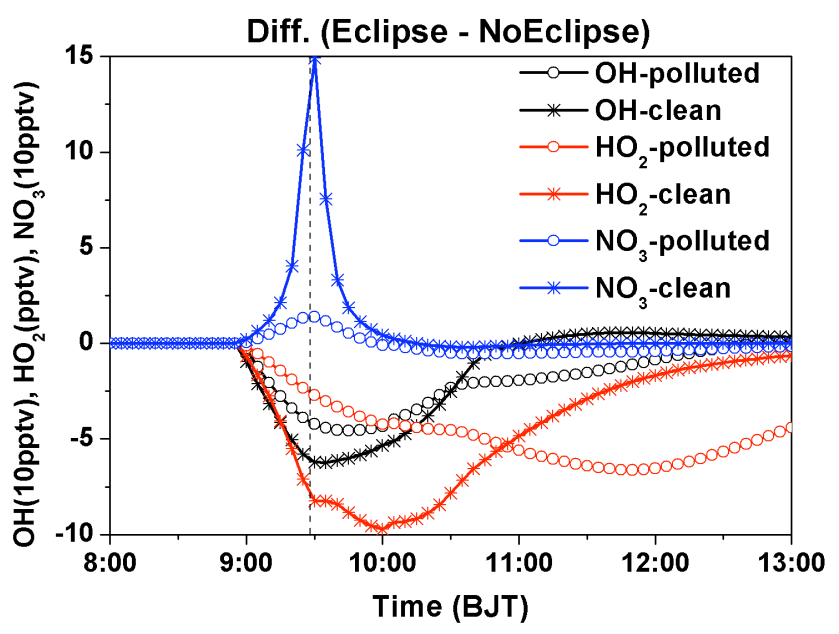

Fig. 10. Time series of differences in $\mathrm{OH}, \mathrm{HO}_{2}$, and $\mathrm{NO}_{3}$ between the Eclipse and NoEclipse runs. The dashed line shows the time of maximum solar eclipse in Beijing.

It is worth noting that the changes in these three radicals in polluted areas are smaller than in clean areas, and are opposite in sign to the changes seen for atmospheric pollutants. This is because production of $\mathrm{OH}$ is mainly from ozone photolysis (to give $\mathrm{O}^{1} \mathrm{D}+\mathrm{H}_{2} \mathrm{O}$ ) in the clean area, while the $\mathrm{HO}_{2}+\mathrm{NO}$ reaction is more important in urban air (Shao et al., 2004). Thus loss of $\mathrm{OH}$ in the clean area is greater due to limited ozone photolysis during the solar eclipse period. Kanaya et al. (2009) showed that $\mathrm{CO}+\mathrm{OH}, \mathrm{RO}_{2}+\mathrm{NO}$, $\mathrm{VOCs}+\mathrm{OH}$ and $\mathrm{HCHO}+h v$ reactions accounted for most of the $\mathrm{HO}_{2}$ production. During the solar eclipse when nighttime chemistry dominates, these reactions are sharply reduced, resulting in loss of $\mathrm{HO}_{2}$. The change in the clean area is more pronounced because $\mathrm{CO}$ and $\mathrm{NO}$ concentrations are lower than in the polluted area, and this leads to less production of $\mathrm{HO}_{2}$. Although the change in radical concentrations in the clean area is larger during the eclipse period, the difference becomes negligible soon after the eclipse. In the polluted
Table 3. Domain-average impacts (as a percentage, \%) of the solar eclipse on photo-oxidants in polluted and clean areas in different phases (according to solar obscuration for each domain: $>50 \%$ coverage, $<50 \%$ coverage, and after eclipse). Values outside the brackets represent the impacts in the polluted area, and values inside brackets represent the clean area. The impact of the eclipse is calculated using the formula: Percentage $=($ Eclipse - NoEclipse $) /$ NoEclipse $\times 100 \%$.

\begin{tabular}{lrrr}
\hline \multirow{2}{*}{ Species } & \multicolumn{3}{c}{ Solar obscuration } \\
\cline { 2 - 4 } & $\begin{array}{r}>50 \% \\
\text { (large obscuration) }\end{array}$ & $\begin{array}{c}<0 \% \\
\text { (small obscuration) }\end{array}$ & $\begin{array}{c}\text { After eclipse } \\
(2 \mathrm{~h})\end{array}$ \\
\hline $\mathrm{O}_{3}$ & $-25.4(-17.7)$ & $-14.3(-8.8)$ & $-6.2(-2.4)$ \\
$\mathrm{NO}_{2}$ & $52.8(75.1)$ & $38.2(31.1)$ & $28.9(9.5)$ \\
$\mathrm{NO}$ & $-50.1(-89.6)$ & $64.1(48.3)$ & $43.8(12.5)$ \\
$\mathrm{CO}$ & $10.4(4.5)$ & $8.0(3.0)$ & $3.9(1.8)$ \\
$\mathrm{OH}$ & $-75.9(-83.6)$ & $-16.9(-4.3)$ & $-0.4(3.5)$ \\
$\mathrm{HO}_{2}$ & $-55.7(-66.2)$ & $-36.0(-17.3)$ & $-17.4(-2.7)$ \\
$\mathrm{NO}_{3}$ & $29.4(62.8)$ & $-8.2(-4.9)$ & $-5.8(-1.9)$ \\
\hline
\end{tabular}

area however, the effect of the eclipse on radical concentrations is still clear for some hours after the eclipse. The impact of the eclipse in the polluted area lasts longer than in the clean area, which is consistent with the findings discussed above. The possible reason is that some paths to $\mathrm{HO}_{\mathrm{x}}$ production are cut off in the polluted area during the eclipse, and are not healed easily even after the solar radiation recovers.

The domain-average impact of the solar eclipse on photooxidants in different areas is shown in Table 3. The impact of the solar eclipse is calculated using the formula: Percentage $=($ Eclipse - NoEclipse $) /$ NoEclipse $\times 100 \%$. We calcu late the average impact in three stages according to the development of the eclipse (solar obscuration $>50 \%,<50 \%$ and $2 \mathrm{~h}$ after the eclipse). The effect of the eclipse on ozone is larger in the polluted area, with a $25 \%$ reduction during the large obscuration period and even $6 \%$ after the eclipse, while the impact is smaller in the clean area, with reductions of $18 \%, 9 \%$ and $2 \%$ in these three stages respectively. $\mathrm{NO}_{\mathrm{x}}$ is more sensitive to the eclipse and the impact during the large obscuration period can reach $50 \%$ in both areas. The impact is more significant in the polluted area, with increases of $29 \%$ in $\mathrm{NO}_{2}$ and $44 \%$ in NO remaining in the $2 \mathrm{~h}$ after the eclipse. The variation in solar radiation during the eclipse results in rapid changes in radicals $\left(\mathrm{OH}, \mathrm{HO}_{2}, \mathrm{NO}_{3}\right)$, especially during the large obscuration period $(>50 \%)$, and the impact in the clean area can be up to $60 \%$ which is largely because of the limited source of radicals in this area. As the solar radiation recovers, the concentration of radicals in the clean area returns to normal rapidly. Therefore, it can be concluded that the effects of the eclipse at its peak are significant in both areas, but that they last longer in polluted areas. 


\section{Summary and discussion}

This study investigates the effects on surface ozone and other photo-oxidants of the total solar eclipse of 22 July 2009, focusing on different regions in China. In order to investigate the sensitivity of ozone to limb darkening during an eclipse event, three experiments addressing eclipse conditions with limb darkening, eclipse conditions without limb darkening and non-eclipse conditions were carried out in a box model. The results reveal that the effect of limb darkening on surface ozone is too small (less than $0.5 \%$ ) to explain the large decrease in surface ozone during a solar eclipse event. Furthermore, a regional model, WRF-Chem, was applied to study the effects of the eclipse on meteorological and chemical parameters. The model was run twice, once with the moving umbra of the Moon, and once without it. The WRF-Chem model captures the basic features of the total eclipse well.

The solar eclipse has maximum impact in the region of totality, with a decrease in surface temperature of $1.5^{\circ} \mathrm{C}$ and decrease in wind speed of $1 \mathrm{~m} \mathrm{~s}^{-1}$. In contrast to the meteorological variables, the maximum impacts on atmospheric pollutants occur over areas of north and east China where emissions are greater, where there is an increase of $5 \mathrm{ppbv}$ in $\mathrm{NO}_{2}$ and $25 \mathrm{ppbv}$ in $\mathrm{CO}$ and a decrease of $10 \mathrm{ppbv}$ in $\mathrm{O}_{3}$ and 4 ppbv in NO.

Furthermore, this study shows the effects of the solar eclipse on surface photo-oxidants in different parts of China. Although the sun was obscured to a smaller extent in polluted areas than in clean areas, the impacts of the eclipse in polluted areas was larger and lasted longer than in clean areas. It is worth noting that there is an increase in NO following the sharp decrease which occurs during the maximum in the eclipse, and this may be related to $\mathrm{NO}_{2}$ photolysis, which leads to accumulation of $\mathrm{NO}$ as the solar radiation recovers. The results also show that changes in surface $\mathrm{CO}$ are mainly due to dynamical processes. The change in radical concentrations during the eclipse reveals that nighttime chemistry dominates in both polluted and clean areas. However, in contrast to the change in atmospheric pollutants, the change in radical concentrations $\left(\mathrm{OH}, \mathrm{HO}_{2}\right.$ and $\left.\mathrm{NO}_{3}\right)$ in clean areas is much greater than that in polluted areas mainly because of the limited source of radicals in these areas.

It is unfortunate that a comprehensive experimental campaign was not organized during the total solar eclipse of 22 July 2009. It is clear that measurement of atmospheric pollutants from only two sites, as used in this study, is not enough. Therefore, we conduct a numerical study using an online model WRF-Chem to investigate the impact of the total eclipse, and reproduce the basic features of this eclipse. However, more observations of atmospheric pollutants are required to validate the numerical model. The solar eclipse provides a natural perturbation to atmospheric chemistry that allows us to test our understanding more thoroughly. Thus it is highly desirable to hold a comprehensive experimental campaign during future solar eclipses. Preparation for these measurements is quite straight-forward given that these are highly predictable events. In particular, high time resolution measurements of the following atmospheric variables are recommended here: (i) ozone $\left(\mathrm{O}_{3}\right)$, nitrogen oxides (NO and $\mathrm{NO}_{2}$ ), (ii) photolysis rates that can be observed, (iii) hydroxyl $(\mathrm{OH})$, hydroperoxy $\left(\mathrm{HO}_{2}\right)$ and nitrate $\left(\mathrm{NO}_{3}\right)$ radicals that show dramatic changes from daytime to nighttime chemistry, (iv) VOCs that are sensitive to solar radiation, and (v) photolysis-related atmospheric constituents that have poorly-known sources, such as HONO.

Acknowledgements. We are grateful to Oliver Wild (Lancaster University, UK) for useful discussions. This work is funded by the Special Fund for Environmental Protection Research in the Public Interest (201009002), the Chinese Academy of Science (KZCX2-YW-205) and the NSFC grant (40775077 and 40805051).

Edited by: S. C. Liu

\section{References}

Abram, J. P., Creasey, D. J., Heard, D. E., Lee, J. D., and Pilling, M. J.: Hydroxyl radical and ozone measurements in England during the solar eclipse of 11 August 1999, Geophys. Res. Lett., 27, 3437-3440, 2000.

Amiridis, V., Melas, D., Balis, D. S., Papayannis, A., Founda, D., Katragkou, E., Giannakaki, E., Mamouri, R. E., Gerasopoulos, E., and Zerefos, C.: Aerosol Lidar observations and model calculations of the Planetary Boundary Layer evolution over Greece, during the March 2006 Total Solar Eclipse, Atmos. Chem. Phys., 7, 6181-6189, doi:10.5194/acp-7-6181-2007, 2007.

Anderson, J.: Meteorological changes during a solar eclipse, Weather, 54(7), 207-215, 1999.

Barnard, J. C., Chapman, E. G., Fast, J. D., Schmelzer, J. R., Slusser, J. R., and Shetter, R. E.: An evaluation of the FAST-J photolysis algorithm for predicting nitrogen dioxide photolysis rates under clear and cloudy sky conditions, Atmos. Environ., 38, 3393-3403, doi:10.1016/j.atmosenv.2004.03.034, 2004.

Dudhia, J.: Numerical Study of Convection Observed during the Winter Monsoon Experiment Using a Mesoscale TwoDimensional Model, J. Atmos. Sci., 46, 3077-3107, 1989.

Emde, C. and Mayer, B.: Simulation of solar radiation during a total eclipse: a challenge for radiative transfer, Atmos. Chem. Phys., 7, 2259-2270, doi:10.5194/acp-7-2259-2007, 2007.

Fabian, P., Rappengluck, B., Stohl, A., Werner, H., Winterhalter, M., Schlager, H., Stock, P., Berresheim, H., Kaminski, U., Koepke, P., Reuder, J., and Birmili, W.: Boundary layer photochemistry during a total solar eclipse, Meteorol. Z., 10, 187-192, 2001.

Fast, J. D., Gustafson, W. I., Easter, R. C., Zaveri, R. A., Barnard, J. C., Chapman, E. G., Grell, G. A., and Peckham, S. E.: Evolution of ozone, particulates, and aerosol direct radiative forcing in the vicinity of Houston using a fully coupled meteorology-chemistry-aerosol model, J. Geophys. Res., 111, D21305, doi:10.1029/2005jd006721, 2006.

Fernandez, W., Castro, V., and Hidalgo, H.: Air-Temperature and Wind Changes in Costa-Rica during the Total Solar Eclipse of July 11, 1991, Earth Moon Planets, 63, 133-147, 1993. 
Fernandez, W., Hidalgo, H., Coronel, G., and Morales, E.: Changes in meteorological variables in Coronel Oviedo, Paraguay, during the total solar eclipse of 3 November 1994, Earth Moon Planets, 74, 49-59, 1996.

Founda, D., Melas, D., Lykoudis, S., Lisaridis, I., Gerasopoulos, E., Kouvarakis, G., Petrakis, M., and Zerefos, C.: The effect of the total solar eclipse of 29 March 2006 on meteorological variables in Greece, Atmos. Chem. Phys., 7, 5543-5553, doi:10.5194/acp7-5543-2007, 2007.

Gerasopoulos, E., Zerefos, C. S., Tsagouri, I., Founda, D., Amiridis, V., Bais, A. F., Belehaki, A., Christou, N., Economou, G., Kanakidou, M., Karamanos, A., Petrakis, M., and Zanis, P.: The total solar eclipse of March 2006: overview, Atmos. Chem. Phys., 8, 5205-5220, doi:10.5194/acp-8-5205-2008, 2008.

Gogosheva, T. N., Petkov, B. K., and Krystev, D. G.: Measurement of ultraviolet radiation and ozone during the solar eclipse of 11 August 1999, Geomagn. Aeronomy, 42, 262-266, 2002.

Grell, G. A., Peckham, S. E., Schmitz, R., McKeen, S. A., Frost, G., Skamarock, W. C., and Eder, B.: Fully coupled "online" chemistry within the WRF model, Atmos. Environ., 39, 6957-6975, doi:10.1016/j.atmosenv.2005.04.027, 2005.

Hanna, E.: Meteorological effects of the solar eclipse of 11 August 1999, Weather, 55, 430-446, 2000.

Janjic, Z. I.: The step-mountain eta coordinate model: Further development of the convection, viscous sub-layer, and turbulent closure schemes, Mon. Weather Rev., 122, 927-945, 1994.

Kanaya, Y., Fukuda, M., Akimoto, H., Takegawa, N., Komazaki, Y., Yokouchi, Y., Koike, M., and Kondo, Y.: Urban photochemistry in central Tokyo: 2. Rates and regimes of oxidant $\left.\left(\mathrm{O}_{(} 3\right)+\mathrm{NO}_{(2)}\right)$ production, J. Geophys. Res., 113, D6301, doi:10.1029/2007JD008671, 2008.

Kazadzis, S., Bais, A., Blumthaler, M., Webb, A., Kouremeti, N., Kift, R., Schallhart, B., and Kazantzidis, A.: Effects of total solar eclipse of 29 March 2006 on surface radiation, Atmos. Chem. Phys., 7, 5775-5783, doi:10.5194/acp-7-5775-2007, 2007.

Koepke, P., Reuder, J., and Schween, J.: Spectral variation of the solar radiation during an eclipse, Meteorol. Z., 10, 179-186, 2001.

Mims, F. M. and Mims, E. R.: Fluctuations in Column Ozone during the Total Solar Eclipse of July 11, 1991, Geophys. Res. Lett., 20, 367-370, 1993.

Mlawer, E. J., Taubman, S. J., Brown, P. D., Iacono, M. J., and Clough, S. A.: Radiative transfer for inhomogeneous atmospheres: RRTM, a validated correlated-k model for the longwave, J. Geophys. Res., 102, 16663-16682, 1997.

Psiloglou, B. E. and Kambezidis, H. D.: Performance of the meteorological radiation model during the solar eclipse of 29 March 2006, Atmos. Chem. Phys., 7, 6047-6059, doi:10.5194/acp-76047-2007, 2007.

Scheffler, H. and Elsässer, H.: Physik der Sterne und der Sonne, 535 pp., Bibliographisches Institut Zürich, Zurich, Switzerland, 1974.

Shao, M., Ren, X. R., Wang, H. X., Zeng, L. M., Zhang, Y. H., and Tang, X. Y.: Quantitative relationship between production and removal of $\mathrm{OH}$ and $\mathrm{HO}_{2}$ radicals in urban atmosphere, Chinese Sci. Bull., 49, 2253-2258, doi:10.1360/04wb0006, 2004.

Srivastava, G. P., Pakkir, M. P. M., and Balwalli, R. R.: Ozone concentration measurements near the ground at Raichur during the solar eclipse of 1980, Proceedings of Indian Natural Sciences Academy, A48(3), 138-142, 1982.
Streets, D. G., Bond, T. C., Carmichael, G. R., Fernandes, S. D., Fu, Q., He, D., Klimont, Z., Nelson, S. M., Tsai, N. Y., Wang, M. Q., Woo, J. H., and Yarber, K. F.: An inventory of gaseous and primary aerosol emissions in Asia in the year 2000, J. Geophys. Res., 108, 8809, doi:10.1029/2002jd003093, 2003.

Tzanis, C.: Ground-based observations of ozone at Athens, Greece during the solar eclipse of 1999, Int. J. Remote. Sens., 26, 35853596, doi:10.1080/01431160500076947, 2005.

Tzanis, C., Varotsos, C., and Viras, L.: Impacts of the solar eclipse of 29 March 2006 on the surface ozone concentration, the solar ultraviolet radiation and the meteorological parameters at Athens, Greece, Atmos. Chem. Phys., 8, 425-430, doi:10.5194/acp-8-425-2008, 2008.

Varotsos, C.: Solar Ultraviolet-Radiation and Total Ozone, as Derived from Satellite and Ground-Based Instrumentation, Geophys. Res. Lett., 21, 1787-1790, 1994.

Varotsos, C.: Airborne measurements of aerosol, ozone, and solar ultraviolet irradiance in the troposphere, J. Geophys. Res., 110, D09202, doi:10.1029/2004jd005397, 2005.

Waldmeier, M.: Ergebnisse und Probleme der Sonnenforschung, Probleme der kosmischen Physik, 264 pp., Akad Verlagsges Becker \& Erler, Leipzig, Germany, 1941.

Wild, O., Zhu, X., and Prather, M. J.: Fast-j: Accurate simulation of in- and below-cloud photolysis in tropospheric chemical models, J. Atmos. Chem., 37, 245-282, 2000.

Zanis, P., Zerefos, C. S., Gilge, S., Melas, D., Balis, D., Ziomas, I., Gerasopoulos, E., Tzoumaka, P., Kaminski, U., and Fricke, W.: Comparison of measured and modeled surface ozone concentrations at two different sites in Europe during the solar eclipse on 11 August 1999, Atmos. Environ., 35, 4663-4673, 2001.

Zanis, P., Katragkou, E., Kanakidou, M., Psiloglou, B. E., Karathanasis, S., Vrekoussis, M., Gerasopoulos, E., Lisaridis, I., Markakis, K., Poupkou, A., Amiridis, V., Melas, D., Mihalopoulos, N., and Zerefos, C.: Effects on surface atmospheric photo-oxidants over Greece during the total solar eclipse event of 29 March 2006, Atmos. Chem. Phys., 7, 6061-6073, doi:10.5194/acp-7-6061-2007, 2007.

Zaveri, R. A. and Peters, L. K.: A new lumped structure photochemical mechanism for large-scale applications, J. Geophys. Res., 104, 30387-30415, 1999.

Zaveri, R. A., Easter, R. C., Fast, J. D., and Peters, L. K.: Model for Simulating Aerosol Interactions and Chemistry (MOSAIC), J. Geophys. Res., 113, D13204, doi:10.1029/2007jd008782, 2008.

Zerefos, C. S, Balis, D. S., Meleti, C., Bais, A. F., Tourpali, K., Vanicek, K., Cappelani, F., Kaminski, U., Tiziano, C., Stubi, R., Formenti, P., and Andreae, A.: Changes in environmental parameters during the solar eclipse of August 11, 1999, over Europe, Effects on surface UV solar irradiance and total ozone, J. Geophys. Res., 105, 26463-26473, 2000.

Zerefos, C. S., Balis, D. S., Zanis, P., Meleti, C., Bais, A. F., Tourpali, K., Melas, D., Ziomas, I., Galani, E., Kourtidis, K., Papayannis, A., and Gogosheva, Z.: Changes in surface UV solar irradiance and ozone over the Balkans during the eclipse of 11 August 1999, Adv. Space Res., 27(12), 1955-1963, 2001.

Zhang, Q., Streets, D. G., Carmichael, G. R., He, K. B., Huo, H., Kannari, A., Klimont, Z., Park, I. S., Reddy, S., Fu, J. S., Chen, D., Duan, L., Lei, Y., Wang, L. T., and Yao, Z. L.: Asian emissions in 2006 for the NASA INTEX-B mission, Atmos. Chem. Phys., 9, 5131-5153, doi:10.5194/acp-9-5131-2009, 2009. 